\title{
Distinct mortality patterns at $0-2$ days versus the remaining neonatal period: results from population-based assessment in the Indian state of Bihar
}

Rakhi Dandona ${ }^{1,2^{*}}$, G. Anil Kumar ${ }^{1}$, Debarshi Bhattacharya ${ }^{3}$, Md. Akbar $^{1}$, Yamini Atmavilas ${ }^{3}$, Priya Nanda ${ }^{3}$ and Lalit Dandona ${ }^{1,2}$

\begin{abstract}
Background: The objectives of this study were to understand the differences in mortality rate, risk factors for mortality, and cause of death distribution in three neonatal age sub-groups $(0-2,3-7$, and $8-27$ days) and assess the change in mortality rate with previous assessments to inform programmatic decision-making in the Indian state of Bihar, a large state with a high burden of newborn deaths.

Methods: Detailed interviews were conducted in a representative sample of 23,602 live births between January and December 2016 (96.2\% participation) in Bihar state. We estimated the neonatal mortality rate (NMR) for the three age sub-groups and explored the association of these deaths with a variety of risk factors using a hierarchical logistic regression model approach. Verbal autopsies were conducted using the PHMRC questionnaire and the cause of death assigned using the SmartVA automated algorithm. Change in NMR from 2011 to 2016 was estimated by comparing it with a previous assessment.

Results: The NMR 0-2-day, 3-7-day, and 8-27-day mortality estimates in 2016 were 24.7 (95\% Cl 21.8-28.0), 13.2 (11.1 to 15.7), 5.8 (4.4 to 7.5), and 5.8 (4.5 to 7.5) per 1000 live births, respectively. A statistically significant reduction of 23.3\% (95\% Cl 9.2\% to 37.3) was seen in NMR from 2011 to 2016, driven by a reduction of 35.3\% (95\% Cl 18.4\% to 52.2) in 0-2-day mortality. In the final regression model, the highest odds for mortality in 0-2 days were related to the gestation period of $\leq 8$ months (OR $16.5,95 \% \mathrm{Cl} 11.9-22.9)$ followed by obstetric complications, no antiseptic cord care, and delivery at a private health facility or home. The 3-7- and 8-27-day mortality was driven by illness in the neonatal period (OR 10.33, 95\% Cl 6.31-16.90, and OR 4.88, 95\% Cl 3.137.61 , respectively) and pregnancy with multiple foetuses (OR 5.15, 95\% Cl 2.39-11.10, and OR $11.77,95 \% \mathrm{Cl} 6.43-$ 21.53, respectively). Birth asphyxia (61.1\%) and preterm delivery (22.1\%) accounted for most of 0-2-day deaths; pneumonia (34.5\%), preterm delivery (33.7\%), and meningitis/sepsis (20.1\%) accounted for the majority of 3-7-day deaths; meningitis/sepsis (30.6\%), pneumonia (29.1\%), and preterm delivery (26.2\%) were the leading causes of death at 8-27 days.

\footnotetext{
* Correspondence: rakhi.dandona@phfi.org

'Public Health Foundation of India, Sector 44, Institutional Area, Gurugram,

National Capital Region, India

${ }^{2}$ Institute for Health Metrics and Evaluation, University of Washington, Seattle,

USA

Full list of author information is available at the end of the article
}

(c) The Author(s). 2019 Open Access This article is distributed under the terms of the Creative Commons Attribution 4.0 International License (http://creativecommons.org/licenses/by/4.0/), which permits unrestricted use, distribution, and reproduction in any medium, provided you give appropriate credit to the original author(s) and the source, provide a link to the Creative Commons license, and indicate if changes were made. The Creative Commons Public Domain Dedication waiver (http://creativecommons.org/publicdomain/zero/1.0/) applies to the data made available in this article, unless otherwise stated. 


\begin{abstract}
(Continued from previous page)
Conclusions: To our knowledge, this is the first study to report a detailed neonatal epidemiology by age sub-groups for a major Indian state, which has highlighted the distinctly different mortality rate, risk factors, and causes of death at $0-2$ days versus the rest of the neonatal period. Monitoring mortality at $0-2$ and $3-7$ days separately in the traditional early neonatal period of $0-7$ days would enable more effective programming to reduce neonatal mortality.
\end{abstract}

Keywords: Bihar, Birth asphyxia, Death, India, Preterm, Meningitis, Neonatal mortality, Risk factors, Sepsis, Verbal autopsy

\section{Background}

The slower reduction in neonatal deaths than the reduction in under- 5 deaths globally in the past two decades has implications on achieving the Every Newborn target of 10 or fewer neonatal deaths per 1000 live births in every country by $2035[1,2]$. India accounted for the largest number of under- 5 deaths in 2016 at 0.9 million $(0.8$ to 0.9 million) in 2016 , and $54.8 \%$ of these were neonatal deaths [2]. As part of the India Newborn Action Plan (INAP), in 2014, the Indian Government adopted a target of $<10$ neonatal deaths per 1000 live births by 2030 as a commitment to end preventable newborn deaths [3].

With substantial heterogeneity in the magnitude and pattern of disease burden across the states of India, it is necessary for the cause burden interventions to be tailored at the state level $[4,5]$. The Indian state of Bihar is the third most populous Indian state with an estimated population of 110 million in 2016, which contributes substantially to neonatal mortality burden in India [4]. The Bill \& Melinda Gates Foundation through the Bihar Technical Support Programme (BTSP) supports the long-term goals of the Government of Bihar to reduce maternal, newborn, and child mortality; improve family planning services; and reduce undernutrition rates in the state [6]. At the start of BTSP in 2011, the neonatal mortality rate (NMR) of 32.2 (95\% CI 27.6-36.8) was estimated for Bihar in the baseline survey [7]. In this paper, we report on the change in NMR since 2011, risk factors for neonatal mortality, cause of death distribution, and place of death in 2016 in three neonatal age sub-groups $(0-2,3-7$, and $8-27$ days) for identifying currently relevant interventions and programme priorities. Importantly, such distinction of the early neonatal mortality (0-7 days) into 0-2- and 3-7-day mortality has not been systematically reported previously from India. By presenting neonatal mortality epidemiology for the age subgroups, these data are not only programmatically relevant for decision-making in Bihar but also have implications for the INAP in the other Indian states with a high burden of newborn deaths.

\section{Methods}

This study was approved by the Institutional Ethics Committee of the Public Health Foundation of India. All participants provided written informed consent, and for those who could not read or write, the participant information sheet and consent form were explained by the trained interviewer and a thumb impression was obtained.

\section{Survey design}

The methods of this survey are detailed elsewhere, and those relevant to this paper are presented [8]. For this current survey, a sample size of 23,200 live births was estimated to detect a change of $17.5 \%$ in neonatal mortality rate in Bihar from 2011 to 2016 with $80 \%$ power. The women were selected by a multistage sampling procedure from Bihar state which is divided into 38 districts, each of which is divided into 5-27 blocks, giving a total of 534 blocks in the state. The aim was to obtain a representative sample of women with a birth between January and December 2016 in the state from $50 \%$ of the 534 blocks for the study. We first stratified the 534 blocks as with only rural population (70.2\%; population range 30,800 to 435 , 700 ) and those with both rural and urban population (29.8\%; population range 74,380 to $1,771,140$ ). We sampled 267 blocks which included 187 (70\%) blocks with only rural population and $80(30 \%)$ blocks with both rural and urban population. Within these 267 blocks, the secondary sampling units (SSUs) were villages in rural areas and urban frame survey blocks in urban areas as defined by the Census 2011 [9]. The SSUs with $<75$ households were combined with an adjacent SSU, and the large rural SSUs were split into equal sized segments of 75-100 households using natural boundaries. A total of 1657 SSUs (1475 rural and 182 urban) were sampled in proportion to the number of SSUs in each block, using systematic random sampling without replacement across all the 267 sampled blocks.

\section{Data collection}

Each selected SSU was mapped and all the households (a household was defined as people eating from the same kitchen) enumerated. During the enumeration, trained interviewers documented the birth outcomes among women aged 15-49 years in each household between January and December 2016. Date of birth, sex of the baby born, and whether it was a live birth or 
stillbirth were documented for each birth. Stillbirths were documented by confirming that the baby did not show any sign of life (did not cry, breathe, and move) in order to differentiate stillbirths and neonatal deaths soon after delivery. We also documented births between January and December 2016 for women who had died during or after giving birth to ensure a robust estimation of total births in this population.

Following enumeration, all women who had reported a birth irrespective of the outcome were eligible for a detailed interview. During the interview, after documenting the background information including socio-demographic characteristics of the participants, questions were asked again to differentiate a stillbirth from a neonatal death that occurred soon after delivery. We documented maternal history during the pregnancy, labour and delivery details, and postnatal care. For babies who had survived for $>2$ days after birth, we also documented the history of illness if any and treatment taken for it during the neonatal period. In addition, verbal autopsy (VA) interviews were conducted for all neonatal deaths using the Population Health Metrics Research Consortium shortened VA questionnaire, which includes close-ended questions and an open narrative to ascertain the cause of death $[10,11]$. The questionnaires were developed in English and then translated into Hindi (local language), after which these were back-translated into English to ensure the accurate and relevant meaning and intent of the questions. Pilot testing of the questionnaires was carried out and modifications made as necessary. Interviews were captured using the Open Development Kit software in hand-held tablets, and interviews were conducted from March to October 2017. Data entered were scrutinized using the internal consistency checks built in to detect and correct errors using the procedures standardized in the baseline study to meet the data quality. About $30 \%$ of the data were collected by the interviewers under direct supervision, and an additional $5 \%$ of the interviews were checked by the supervisors by visiting the respondent again. The most frequent discrepancies identified in the initial rounds of data collection were a mismatch of women's age based on various administrative records, number of antenatal care (ANC) visits, and over-reporting of swelling of the hands and feet under maternal complications. These errors were corrected, and re-training was undertaken for the interviewers.

\section{Analysis}

Before the analysis, we reviewed the narratives of neonates who had died on the day of birth (day 0 ) to check for possible misreporting between neonatal death and stillbirth. A total of 3 neonatal deaths were reassigned as stillbirth, and no stillbirth was reassigned as a neonatal death. Neonatal death was defined as death within the first 28 days of birth (0-27 days) [12]. We estimated the overall neonatal mortality rate (NMR) per 1000 live births and also in three sub-categories of $0-2$ days, 3-7 days, and 8-27 days. NMR was also estimated by sex and place of residence for the state of Bihar in the year 2016. The change in the overall NMR from 2011 to 2016 for Bihar was also estimated [7]. The rates were adjusted for Bihar's population, and 95\% confidence interval $(\mathrm{CI})$ is reported.

\section{Risk factors for neonatal mortality}

We investigated the association of neonatal deaths for the three age sub-categories with a variety of risk factors, including socio-demographic factors, maternal risk factors, pregnancy, and labour- and delivery-related factors. In addition to these, the risk factors in the postnatal care period were included in models for 3-7-day and 8-27day deaths. Distribution of and results of unadjusted simple logistic regression are reported for all risk factors that were assessed for all the three models. Furthermore, the associations between the risk factors for neonatal deaths for the three age sub-categories were explored using a hierarchical approach to build the logistic regression model that gave importance to the distal determinants of neonatal mortality [13, 14]. We ran 5 models for $0-2$ days and 6 models for 3-7 and 8-27 days deaths with each model adjusted for place of residence and sex of the baby, and each sequential model incorporated variables from the preceding model if $P$ was $<0.2$ (value for at least one category to be $<0.2$ for multiple category variables) [15]. Birthweight was not considered in the adjusted logistic regression as it was not available for $31.4 \%$ babies. Wealth index was estimated using the standard questions and methods used in the National Family Health Surveys [16]. For the health facility deliveries, we additionally documented if they had gone to another facility for delivery prior to giving birth in the facility where they gave birth (termed as "referral"). We ran the adjusted models for the three sub-categories for only facility births by including referral delivery as a risk factor. Odds ratio with 95\% CI is presented for all models of regression results. All analysis was performed using STATA 13.1 software (Stata Corp., USA).

\section{Cause and place of death}

As per the Population Health Metrics Research Consortium protocol, the cause of neonatal death was assigned using the validated SmartVA automated algorithm $[10,17,18]$. The cause of neonatal deaths is presented separately for the three sub-categories by the place of delivery. We also report on the place of death for the neonates by place of delivery. For the facility births, we also report the mean days of stay after birth before discharge from the facility. 


\section{Results}

A total of 23,602 live births in the year 2016 were identified in 182,486 households (96.2\% participation) covering a population of 945,216 . A total of 564 neonatal deaths were identified giving an estimated NMR of 24.7 (95\% CI 21.8-28.0) per 1000 live births for the state (Table 1). A statistically significant reduction of $23.3 \%$ (95\% CI - 37.3 to -9.2 ) in the overall NMR was documented from 2011 to 2016, an annualized compounded reduction of $5.2 \%$ (Table 1 ). Among the neonatal deaths, 330 (58.5\%) were within 0-2 days, 111 (19.7\%) in 3-7 days, and $123(21.8 \%)$ in 8-27 days of birth. The NMR by the age sub-categories is shown in Table 1 . The largest decline in NMR from 2011 to 2016 was in 0-2-day mortality $(-35.3,95 \%$ CI -52.2 to -18.4$)$. A decline of borderline significance at $20.1 \%$ was documented for NMR in boys, and the NMR for boys and girls was similar in 2016 (Table 1).

\section{Risk factors for neonatal mortality}

Of the total live births identified in the enumeration, the detailed interview data were available for 19,877 (84.2\% participation) live births including 473 neonatal deaths (83.9\% participation). Variations were seen in the distribution and associations of the risk factors using the unadjusted logistic regression for neonatal deaths in the three sub-categories (Table 2). Of all live births, 10,623 (53.5\%), 3314 (16.7\%), and $5922(29.8 \%)$ were at a public health facility, private health facility, and at home, respectively. Of the 473 neonatal deaths, 216 (45.7\%), 121 (25.6\%), and $136(28.7 \%)$ were at a public health facility, private health facility, and at home, respectively. The distribution of risk factors by place of delivery for the three sub-categories of neonatal deaths is shown in Additional file 1: Table S1.

After adjusting for the place of residence and sex of the neonate in the final sequential logistic regression model for mortality in 0-2 days (Table 3), gestation period of $\leq 8$ months had the highest odds for mortality in this period (OR 16.52, 95\% CI 11.93-22.88) followed by obstetric complications including push/ pull during the delivery by health provider (OR 2.88, 95\% CI 1.93-4.32), breech position of the baby (OR 2.70, 95\% CI 1.72-4.25), entangled cord around the baby's neck (OR 2.02, 95\% CI 1.23-3.34), and pregnancy with multiple foetuses (OR 2.31, 95\% CI 1.304.11). Not receiving antiseptic cord care at birth (OR 2.40, 95\% CI 1.60-3.59) and delivery either at private health facility or at home (OR 1.58, 95\% CI 1.212.06) also had significantly higher odds of death in 0 2 days. The neonates belonging to any wealth index quartile other than the highest quartile 4 (OR 1.83, 95\% CI 1.28-2.59), primi babies (OR 1.44, 95\% CI 1.07-1.93), babies of women who did not receive tetanus toxoid (TT) immunization during pregnancy (OR 1.54, 95\% CI 1.14-2.09), and boy babies (OR 1.32 , 95\% CI 1.02-1.71) also had significantly higher odds of death in 0-2 days.

For mortality at 3-7 days (Table 4), illness in the neonatal period (OR 10.33, 95\% CI 6.31-16.90) had the highest odds of death followed by pregnancy with multiple foetuses (OR 5.15, 95\% CI 2.39-11.10), gestation period of $\leq 8$ months (OR 3.76, 95\% CI 1.87-7.58), and babies who were put in an incubator after birth (OR 3.28, 95\% CI 1.88-5.75). Pregnancies with no antenatal care (OR 1.98, 95\% CI 1.18-3.34), without TT

Table 1 Neonatal mortality rate (NMR) in 2011 (reference [7]) and 2016 in the Indian state of Bihar by age at death, sex, and place of residence

\begin{tabular}{|c|c|c|c|}
\hline & \multicolumn{2}{|c|}{ Mortality rate per 1000 live births (95\% confidence interval) } & \multirow{2}{*}{$\begin{array}{l}\text { Percent change in } \\
\text { mortality rate from } 2011 \text { to } 2016 \\
(95 \% \text { confidence interval) }\end{array}$} \\
\hline & 2011 & 2016 & \\
\hline \multicolumn{4}{|c|}{ NMR by age at death } \\
\hline $0-2$ days & 20.4 (16.9 to 23.9$)$ & $13.2(11.1$ to 15.7$)$ & $-35.3(-52.2$ to -18.4$)$ \\
\hline $3-7$ days & 6.7 (4.7 to 8.7$)$ & $5.8(4.4$ to 7.5$)$ & $-13.4(-39.9$ to 13.0$)$ \\
\hline $8-27$ days & $5.0(3.0$ to 6.9$)$ & $5.8(4.5$ to 7.5$)$ & $16.0(-17.0$ to 49.0$)$ \\
\hline $0-7$ days & $27.0(23.2$ to 30.9$)$ & 18.9 (16.4 to 21.8$)$ & $-30.0(-44.9$ to -15.1$)$ \\
\hline $3-27$ days & $11.6(8.4$ to 14.9$)$ & $11.6(9.6$ to 14.0$)$ & $0.0(-22.7$ to 22.7$)$ \\
\hline $0-27$ days & 32.2 (27.6 to 36.8$)$ & 24.7 (21.8 to 28.0$)$ & $-23.3(-37.3$ to -9.2$)$ \\
\hline \multicolumn{4}{|l|}{ NMR by sex } \\
\hline Boy & 32.9 (27.2 to 39.8$)$ & 26.3 (22.7 to 30.6$)$ & $-20.1(-42.0$ to 1.9$)$ \\
\hline Girl & 21.5 (17.4 to 26.7$)$ & 23.0 (18.7 to 28.2$)$ & $7.0(-20.9$ to 34.8$)$ \\
\hline \multicolumn{4}{|c|}{ NMR by place of residence } \\
\hline Rural & 32.3 (27.4 to 37.2$)$ & 25.3 (22.2 to 28.8 ) & $-21.7(-37.5$ to -5.9$)$ \\
\hline Urban & 25.5 (16.5 to 34.5$)$ & $16.0(9.2$ to 27.4$)$ & $-37.3(-70.0$ to -4.5$)$ \\
\hline
\end{tabular}




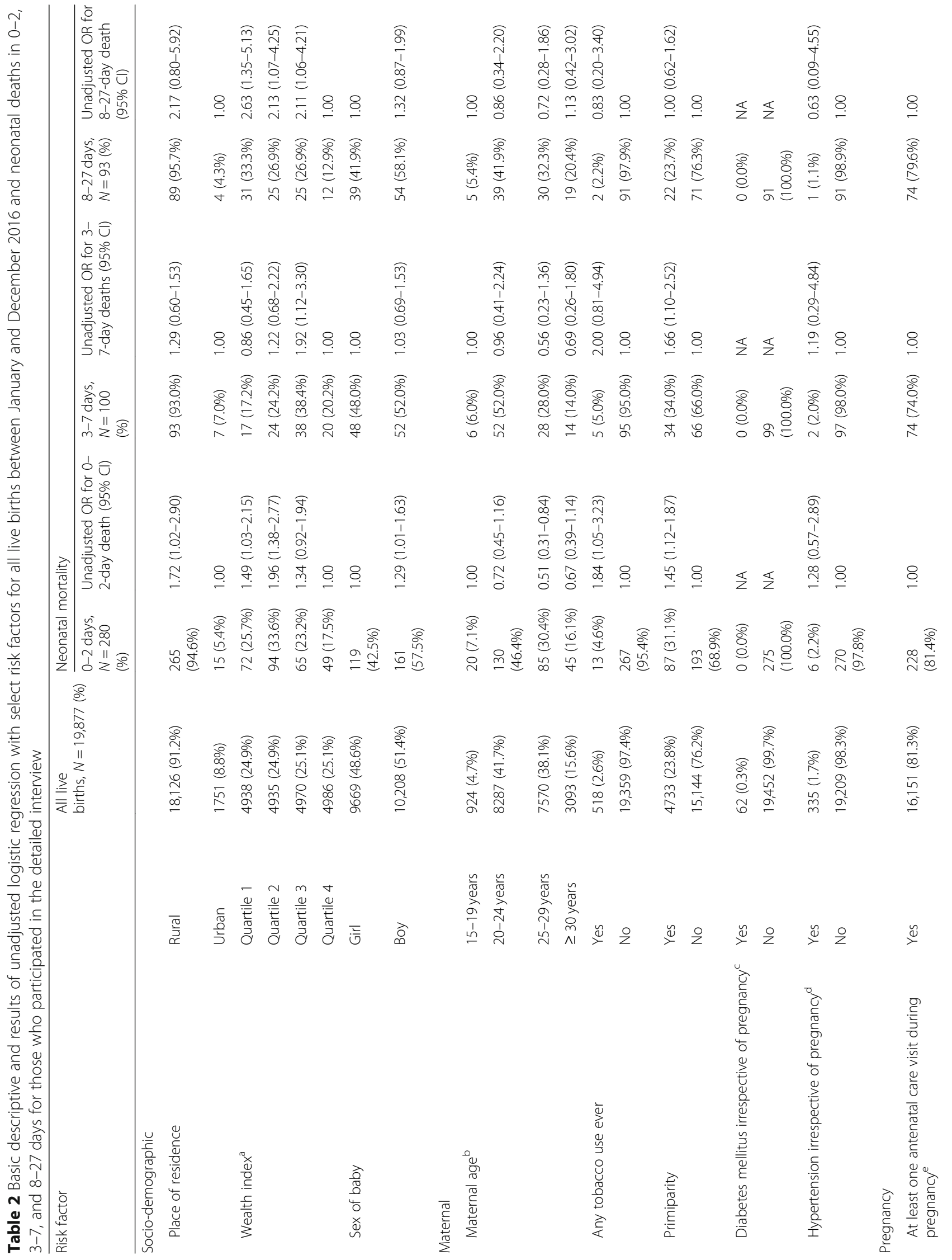




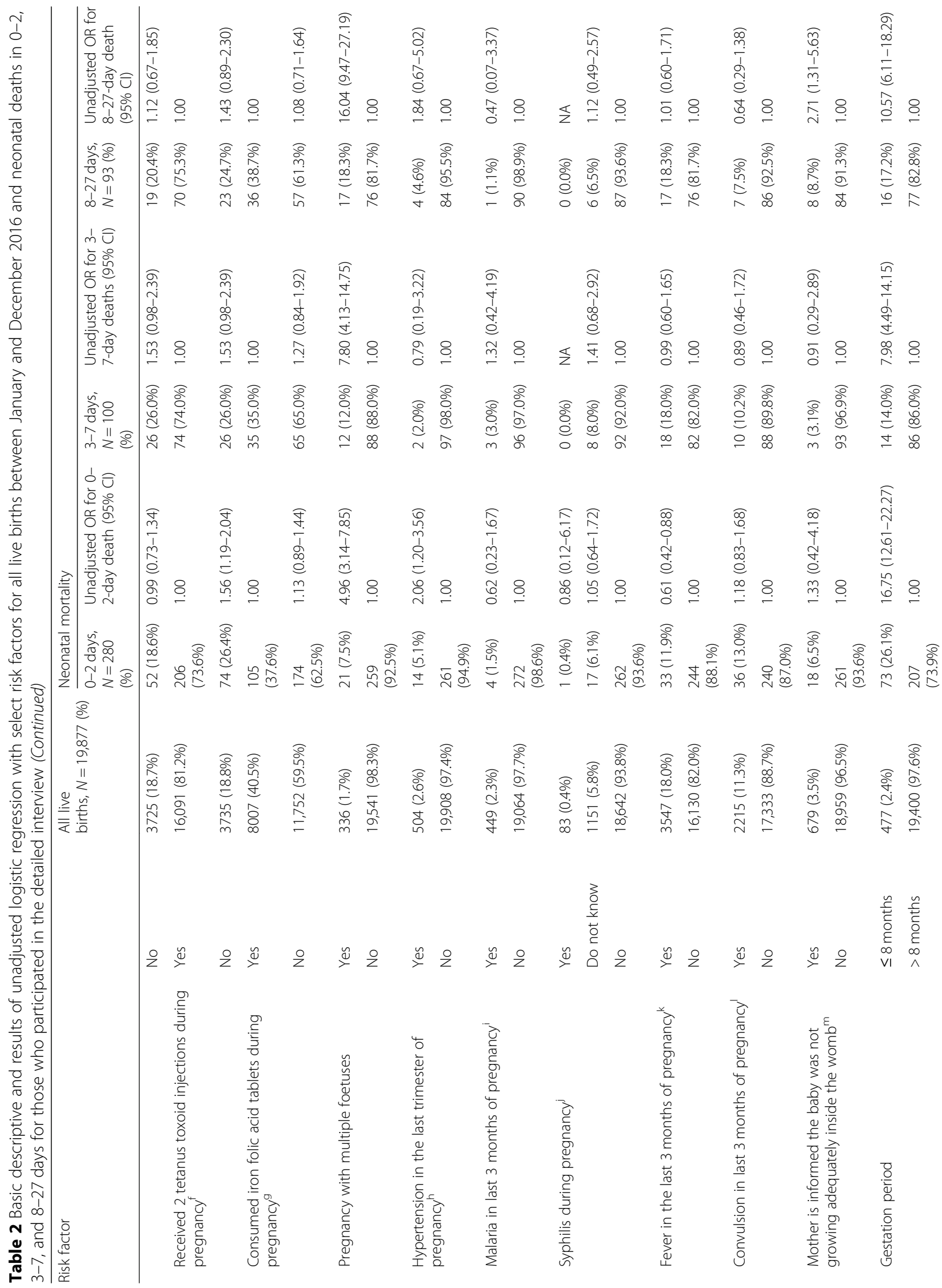




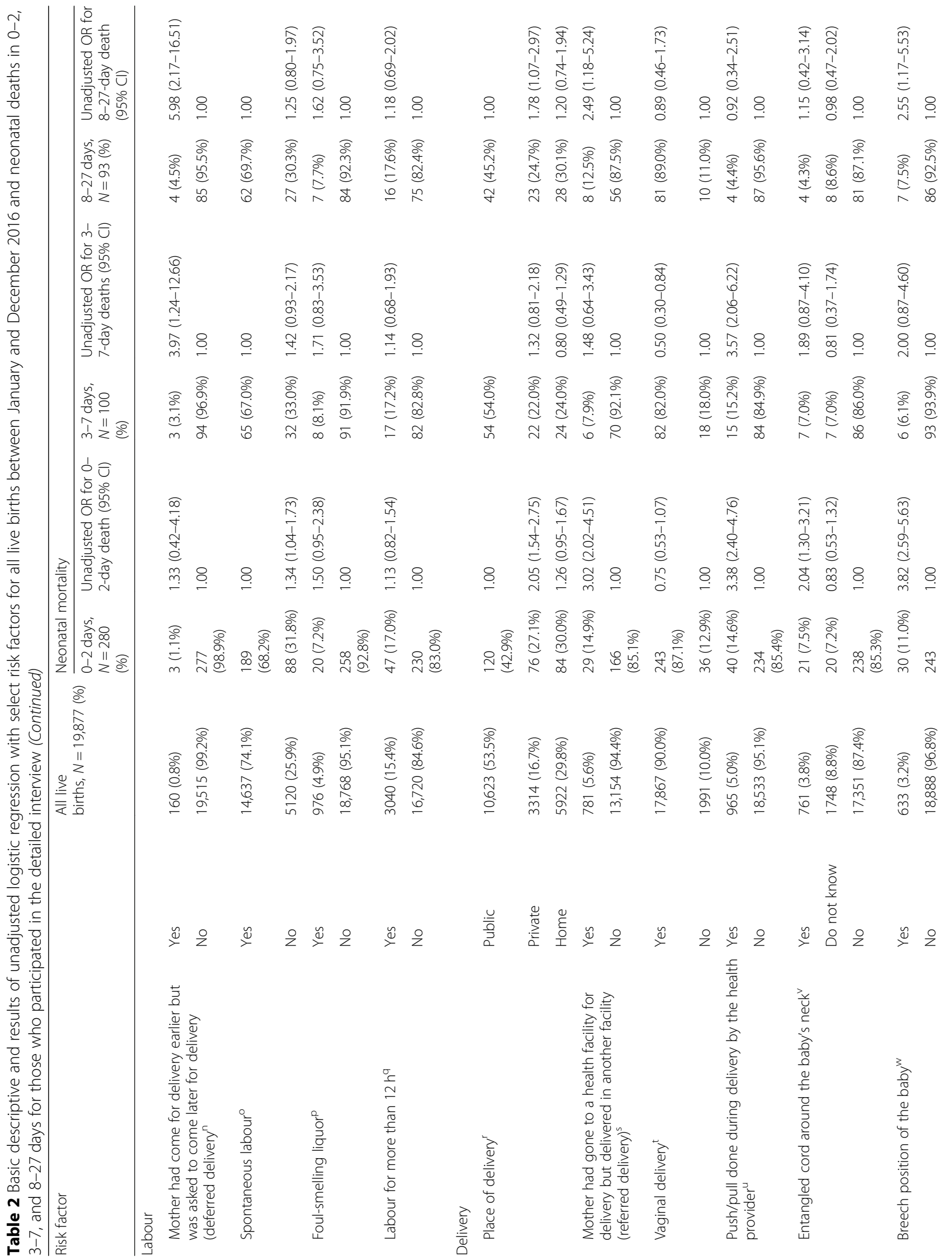




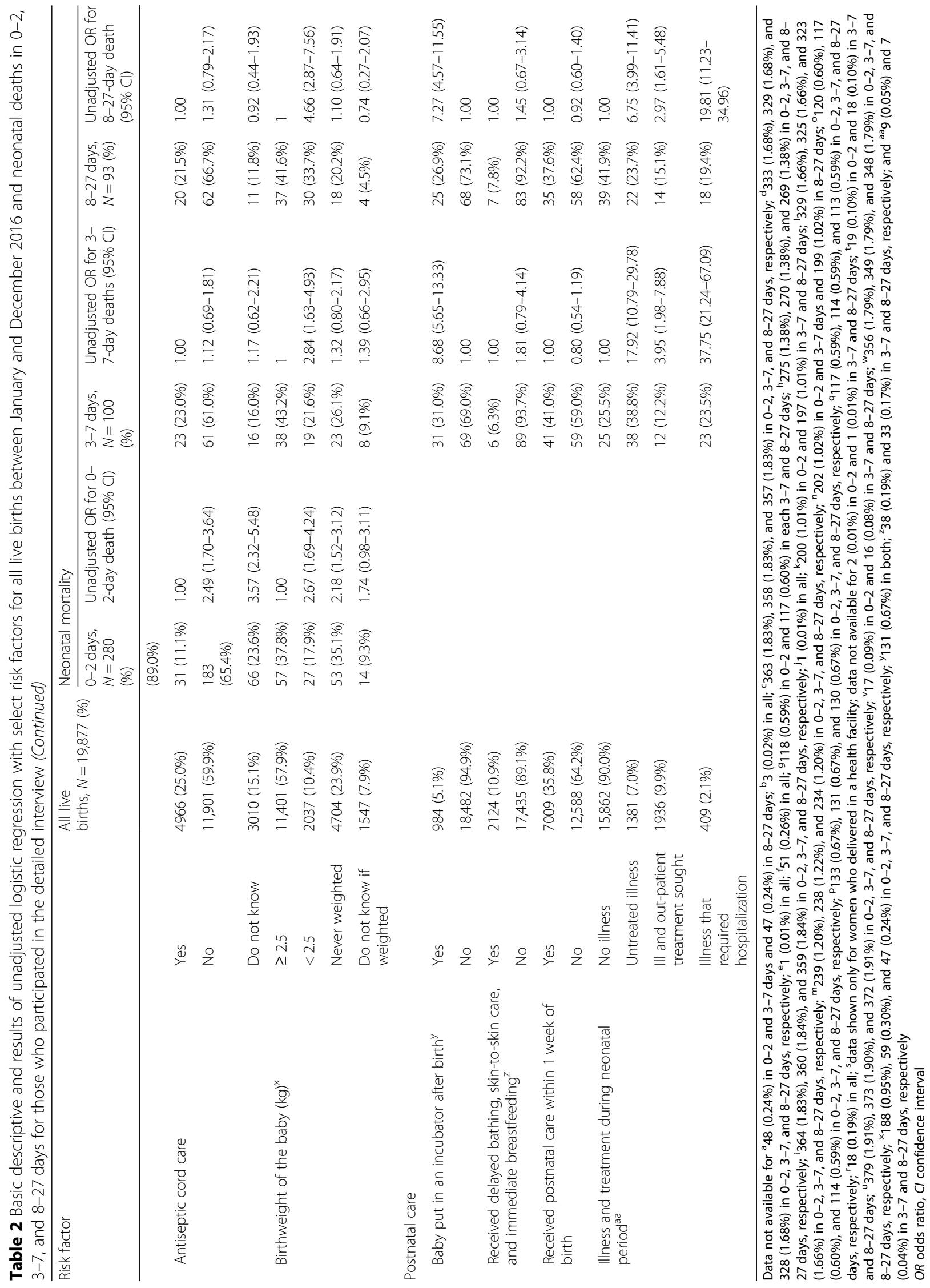


Table 3 Results of sequential multiple logistic regression models for the association of neonatal death within 0-2 days of birth with select risk factors in the Indian state of Bihar

\begin{tabular}{|c|c|c|c|c|c|}
\hline \multirow[t]{2}{*}{ Risk factors } & \multicolumn{5}{|c|}{ Adjusted odds ratio for neonatal death in $0-2$ days (95\% confidence interval) } \\
\hline & Model $1^{*}$ & Model $2^{*}$ & Model $3^{*}$ & Model $4^{*}$ & Model $5^{*}$ \\
\hline Rural place of residence & $1.45(0.85-2.47)$ & $1.40(0.82-2.39)$ & $1.50(0.85-2.65)$ & $1.56(0.89-2.74)$ & $1.43(0.79-2.56)$ \\
\hline Boy baby & $1.29(1.01-1.63)$ & $1.27(1.00-1.62)$ & $1.37(1.07-1.77)$ & $1.35(1.05-1.73)$ & $1.32(1.02-1.71)$ \\
\hline \multicolumn{6}{|l|}{ Wealth index quartile } \\
\hline । & $1.41(0.98-2.05)$ & $1.50(1.02-2.18)$ & $2.02(1.35-3.02)$ & $1.86(1.25-2.77)$ & $2.01(1.31-3.07)$ \\
\hline$\|$ & $1.85(1.30-2.64)$ & $1.89(1.32-2.71)$ & $2.30(1.56-3.37)$ & $2.23(1.53-3.25)$ & $2.41(1.61-3.60)$ \\
\hline III & $1.28(0.88-1.87)$ & $1.31(0.90-1.93)$ & $1.45(0.97-2.16)$ & $1.33(0.89-1.99)$ & $1.46(0.96-2.22)$ \\
\hline IV & 1.00 & 1.00 & 1.00 & 1.00 & 1.00 \\
\hline \multicolumn{6}{|l|}{ Maternal age } \\
\hline $15-19$ years & & 1.00 & 1.00 & 1.00 & \\
\hline 20-24 years & & $0.81(0.50-1.33)$ & $0.81(0.49-1.35)$ & $0.94(0.56-1.60)^{\ddagger}$ & \\
\hline $25-29$ years & & $0.64(0.37-1.11)$ & $0.69(0.39-1.21)$ & $0.79(0.45-1.41)^{\ddagger}$ & \\
\hline$\geq 30$ years & & $0.81(0.45-1.46)$ & $0.76(0.41-1.40)$ & $0.81(0.43-1.53)^{\ddagger}$ & \\
\hline Any tobacco use ever & & $1.75(0.99-3.10)$ & $1.73(0.95-3.14)$ & $1.79(0.99-3.26)$ & $1.64(0.90-2.99)$ \\
\hline Primiparity & & $1.37(1.01-1.86)$ & $1.41(1.02-1.96)$ & $1.43(1.03-1.98)$ & $1.44(1.07-1.93)$ \\
\hline $\begin{array}{l}\text { Maternal history of high blood pressure } \\
\text { irrespective of pregnancy }\end{array}$ & & $1.28(0.57-2.90)^{\ddagger}$ & & & \\
\hline $\begin{array}{l}\text { No maternal antenatal care visit during } \\
\text { pregnancy }\end{array}$ & & & $1.00(0.71-1.39)^{\ddagger}$ & & \\
\hline $\begin{array}{l}\text { Mother did not receive } 2 \text { tetanus toxoid injections } \\
\text { during pregnancy }\end{array}$ & & & $1.52(1.13-2.05)$ & $1.49(1.11-2.00)$ & $1.54(1.14-2.09)$ \\
\hline $\begin{array}{l}\text { Mother did not consume iron folic acid tablets } \\
\text { during pregnancy }\end{array}$ & & & $0.99(0.76-1.28)^{\ddagger}$ & & \\
\hline Pregnancy with multiple foetuses & & & $2.92(1.72-4.95)$ & $3.33(1.96-5.64)$ & $2.31(1.30-4.11)$ \\
\hline $\begin{array}{l}\text { Maternal hypertension in the last trimester } \\
\text { of pregnancy }\end{array}$ & & & $2.00(1.06-3.77)$ & $1.82(0.99-3.36)$ & $1.34(0.68-2.66)$ \\
\hline $\begin{array}{l}\text { Mother had malaria in the last trimester } \\
\text { of pregnancy }\end{array}$ & & & $0.66(0.23-1.90)^{\ddagger}$ & & \\
\hline \multicolumn{6}{|l|}{ Diagnosed with syphilis during pregnancy } \\
\hline No & & & 1.00 & & \\
\hline Yes & & & $1.43(0.19-10.66)^{\ddagger}$ & & \\
\hline Do not know & & & $1.06(0.63-1.80)^{\ddagger}$ & & \\
\hline $\begin{array}{l}\text { Mother had a fever in the last } \\
3 \text { months of pregnancy }\end{array}$ & & & $0.57(0.39-0.85)$ & $0.56(0.38-0.83)$ & $0.49(0.32-0.74)$ \\
\hline $\begin{array}{l}\text { Mother had convulsions in the } \\
\text { last } 3 \text { months of pregnancy }\end{array}$ & & & $0.94(0.64-1.38)^{\ddagger}$ & & \\
\hline $\begin{array}{l}\text { Mother is informed the baby was } \\
\text { not growing adequately } \\
\text { inside the womb }\end{array}$ & & & $1.44\left(0.81-2.54^{\ddagger}\right)$ & & \\
\hline \multicolumn{6}{|l|}{ Gestation period } \\
\hline$\leq 8$ months & & & $16.74(12.26-22.86)$ & $17.03(12.50-23.20)$ & $16.52(11.93-22.88)$ \\
\hline$>8$ months & & & 1.00 & 1.00 & 1.00 \\
\hline Deferred delivery & & & & $0.84(0.25-2.83)^{\ddagger}$ & \\
\hline Spontaneous labour & & & & $1.30(0.99-1.71)$ & $1.38(1.03-1.84)$ \\
\hline Foul-smelling liquor & & & & $1.46(0.88-2.42)$ & $1.12(0.64-1.96)$ \\
\hline Labour for more than $12 \mathrm{~h}$ & & & & $1.07(0.76-1.51)^{\ddagger}$ & \\
\hline
\end{tabular}

Place of delivery 
Table 3 Results of sequential multiple logistic regression models for the association of neonatal death within 0-2 days of birth with select risk factors in the Indian state of Bihar (Continued)

\begin{tabular}{|c|c|c|c|c|c|}
\hline \multirow[t]{2}{*}{ Risk factors } & \multicolumn{5}{|c|}{ Adjusted odds ratio for neonatal death in 0-2 days ( $95 \%$ confidence interval) } \\
\hline & Model $1^{*}$ & Model $2^{*}$ & Model $3^{*}$ & Model $4^{*}$ & Model $5^{*}$ \\
\hline Public facility & & & & & 1.00 \\
\hline Private facility & & & & & $1.88(1.31-2.70)$ \\
\hline Home & & & & & $1.39(1.02-1.90)$ \\
\hline Vaginal delivery & & & & & $1.26(0.79-2.00)$ \\
\hline $\begin{array}{l}\text { Push/pull done during delivery by } \\
\text { the health provider }\end{array}$ & & & & & $2.88(1.93-4.32)$ \\
\hline \multicolumn{6}{|l|}{$\begin{array}{l}\text { Entangled cord around the } \\
\text { baby's neck }\end{array}$} \\
\hline No & & & & & 1.00 \\
\hline Yes & & & & & $2.02(1.23-3.34)$ \\
\hline Do not know & & & & & $0.60(0.34-1.07)$ \\
\hline Breech presentation of the baby & & & & & $2.70(1.72-4.25)$ \\
\hline \multicolumn{6}{|l|}{ Antiseptic cord care } \\
\hline Yes & & & & & 1.00 \\
\hline No & & & & & $2.40(1.60-3.59)$ \\
\hline Do not know & & & & & $3.85(2.44-6.10)$ \\
\hline
\end{tabular}

*Model adjusted for sex of the baby and place of residence

${ }^{\ddagger} P \geq 0.2$ and hence excluded from the sequential model

immunization during pregnancy (OR 1.94, 95\% CI 1.193.16 ), and those belonging to wealth index quartile 3 (OR 2.71, 95\% CI 1.42-5.16) also had significantly higher odds of death in 3-7 days. For deaths at 8-27 days (Table 5), pregnancy with multiple foetuses (OR 11.77, 95\% CI 6.43-21.53), illness in the neonatal period (OR $4.88,95 \%$ CI $3.13-7.61)$, and gestation period of $\leq 8$ months (OR 6.15, 95\% CI 3.18-11.87) had significantly higher odds of death. The babies who were put in an incubator after birth (OR 2.72, 95\% CI 1.49-4.96) and those belonging to any wealth index quartile other than quartile 4 (OR 3.04, 95\% CI 1.53-6.04) also had significantly higher odds of death at 8-27 days.

As illness during the neonatal period had the highest odds of death at 3-27 days, illness symptoms and treatment sought were explored among the neonates who had survived for 3 days or more (Additional file 3: Figure S1). High fever (10.1\%) was the most commonly reported symptom followed by loss of interest in breastfeeding (4.4\%), difficult/rapid breathing (4.1\%), and baby is cold to touch (4.1\%). Among those with reported illness, most treatments were sought for high fever (73\%) and yellowing of the skin (69.3\%) and the least for baby drowsy/difficult to awaken (24.8\%) and discoloration of the skin around the cord (23.9\%).

On considering referred deliveries as a risk factor for the facility births (data not shown), referral delivery was significantly associated with mortality at 0-2 days (OR
2.35, 95\% CI 1.44-3.83) with no significant change in the results of the previous model. No significant association of referred deliveries was found with mortality at $3-7$ and $8-27$ days.

\section{Place of death}

Overall, 227 (48\%), 46 (9.7\%), and 200 (42.3\%) of the neonates had died at a facility, en route to a facility, and at home, respectively. By place of delivery, $57.4 \%$, 76.9\%, and $7.4 \%$ of the births at a public facility, private facility, and at home had died at a facility, respectively. Distribution of place of death varied by age at death and place of delivery (Fig. 1). In 0-2-day deaths, majority of the facility deaths were also facility births $(81.1 \%)$ and the majority of home deaths were home births (85.7\%). In 3-7and 8-27-day deaths, the proportion of facility deaths was higher for the private facility births as compared with the public facility and home births.

Among the 13,961 (70.2\%) health facility births, the mean days of stay at the facility for neonates before discharge were significantly lower at the public as compared with the private facilities both for those who survived and those who died during the neonatal period (Additional file 2: Table S2). Importantly, $62.5 \%$ and $48.7 \%$ of the neonates who had died at $0-2$ days were discharged alive from the public and private facility after birth, respectively. The mean stay at the facility for these neonates was 4.2 times shorter in the public as 
Table 4 Results of sequential multiple logistic regression models for the association of neonatal deaths in 3-7 days after birth with select risk factors in the Indian state of Bihar

\begin{tabular}{|c|c|c|c|c|c|c|}
\hline \multirow[t]{2}{*}{ Risk factors } & \multicolumn{6}{|c|}{ Adjusted odds ratio for neonatal death in 3-7 days ( $95 \%$ confidence interval) } \\
\hline & Model $1^{*}$ & Model $2^{*}$ & Model 3* & Model $4^{*}$ & Model $5^{*}$ & Model $6^{*}$ \\
\hline Rural place of residence & $1.21(0.55-2.67)$ & $1.15(0.52-2.54)$ & $1.10(0.49-2.47)$ & $1.30(0.55-3.10)$ & $1.56(0.61-4.03)$ & $0.79(0.34-1.82)$ \\
\hline Boy baby & $1.06(0.71-1.57)$ & $1.09(0.73-1.62)$ & $1.13(0.75-1.70)$ & $1.19(0.78-1.80)$ & $1.20(0.79-1.82)$ & $1.04(0.67-1.62)$ \\
\hline \multicolumn{7}{|l|}{ Wealth index quartile } \\
\hline I & $0.84(0.43-1.62)$ & $0.92(0.47-1.80)$ & $0.89(0.44-1.79)$ & $0.73(0.34-1.57)$ & $0.91(0.42-1.96)$ & $1.18(0.54-2.55)$ \\
\hline$\|$ & $1.19(0.65-2.18)$ & $1.29(0.69-2.39)$ & $1.20(0.63-2.28)$ & $1.41(0.74-2.71)$ & $1.55(0.79-3.05)$ & $1.57(0.77-3.21)$ \\
\hline III & $1.87(1.08-3.25)$ & $2.03(1.16-3.57)$ & $1.94(1.09-3.47)$ & $2.23(1.22-4.04)$ & $2.43(1.31-4.52)$ & $2.71(1.42-5.16)$ \\
\hline IV & 1.00 & 1.00 & 1.00 & 1.00 & 1.00 & 1.00 \\
\hline \multicolumn{7}{|l|}{ Maternal age } \\
\hline $15-19$ years & & 1.00 & & & & \\
\hline $20-24$ years & & $1.07(0.45-2.55)^{\ddagger}$ & & & & \\
\hline $25-29$ years & & $0.74(0.28-1.92)^{\ddagger}$ & & & & \\
\hline$\geq 30$ years & & $0.89(0.32-2.53)^{\ddagger}$ & & & & \\
\hline Any tobacco use ever & & $2.23(0.89-5.59)$ & $1.72(0.62-4.79)^{\ddagger}$ & & & \\
\hline Null parity & & $1.38(0.84-2.26)^{\ddagger}$ & & & & \\
\hline $\begin{array}{l}\text { Maternal history of high blood pressure } \\
\text { irrespective of pregnancy }\end{array}$ & & $1.20(0.29-4.90)^{\ddagger}$ & & & & \\
\hline $\begin{array}{l}\text { No maternal antenatal care visit during } \\
\text { pregnancy }\end{array}$ & & & $1.47(0.89-2.44)$ & $1.87(1.15-3.03)$ & $1.88(1.14-3.10)$ & $1.98(1.18-3.34)$ \\
\hline $\begin{array}{l}\text { Mother did not receive } 2 \text { tetanus toxoid } \\
\text { injections during pregnancy }\end{array}$ & & & $1.58(0.99-2.52)$ & $1.45(0.90-2.33)$ & $1.61(1.00-2.59)$ & $1.94(1.19-3.16)$ \\
\hline $\begin{array}{l}\text { Mother did not consume iron folic acid } \\
\text { tablets during pregnancy }\end{array}$ & & & $1.11(0.72-1.71)^{\ddagger}$ & & & \\
\hline Pregnancy with multiple foetuses & & & $6.13(3.11-12.07)$ & $6.35(3.16-12.75)$ & $5.28(2.50-11.15)$ & $5.15(2.39-11.10)$ \\
\hline $\begin{array}{l}\text { Maternal hypertension in the last trimester } \\
\text { of pregnancy }\end{array}$ & & & $0.75(0.17-3.19)^{\ddagger}$ & & & \\
\hline $\begin{array}{l}\text { Mother had malaria in the last trimester } \\
\text { of pregnancy }\end{array}$ & & & $1.54(0.46-5.14)^{\ddagger}$ & & & \\
\hline \multicolumn{7}{|l|}{ Diagnosed with syphilis during pregnancy } \\
\hline No & & & 1.00 & & & \\
\hline Yes & & & NA & & & \\
\hline Do not know & & & $1.60(0.76-3.36)^{\ddagger}$ & & & \\
\hline $\begin{array}{l}\text { Mother had a fever in the last } 3 \text { months } \\
\text { of pregnancy }\end{array}$ & & & $1.07(0.63-1.82)^{\ddagger}$ & & & \\
\hline $\begin{array}{l}\text { Mother had convulsions in the last } 3 \text { months } \\
\text { of pregnancy }\end{array}$ & & & $0.95(0.49-1.87)^{\ddagger}$ & & & \\
\hline $\begin{array}{l}\text { Mother is informed the baby was not growing } \\
\text { adequately inside the womb }\end{array}$ & & & $0.75(0.23-2.48)^{\ddagger}$ & & & \\
\hline \multicolumn{7}{|l|}{ Gestation period } \\
\hline 8 months or less & & & $6.99(3.76-13.00)$ & $6.13(3.20-11.76)$ & $6.40(3.31-12.38)$ & $3.76(1.87-7.58)$ \\
\hline$>8$ months & & & 1.00 & 1.00 & 1.00 & 1.00 \\
\hline Deferred delivery & & & & $2.68(0.77-9.29)$ & $3.04(0.90-10.31)$ & $2.00(0.53-7.53)$ \\
\hline Spontaneous labour & & & & $1.45(0.93-2.28)$ & $1.31(0.83-2.08)^{\ddagger}$ & \\
\hline Foul-smelling liquor & & & & $1.58(0.74-3.39)^{\ddagger}$ & & \\
\hline Labour for more than $12 \mathrm{~h}$ & & & & $1.05(0.60-1.83)^{\ddagger}$ & & \\
\hline \multicolumn{7}{|l|}{ Place of delivery } \\
\hline Public facility & & & & & 1.00 & \\
\hline Private facility & & & & & $0.90(0.47-1.70)^{\ddagger}$ & \\
\hline Home & & & & & $0.88(0.52-1.49)^{\ddagger}$ & \\
\hline Vaginal delivery & & & & & $0.54(0.27-1.09)$ & $0.58(0.31-1.07)$ \\
\hline
\end{tabular}


Table 4 Results of sequential multiple logistic regression models for the association of neonatal deaths in 3-7 days after birth with select risk factors in the Indian state of Bihar (Continued)

\begin{tabular}{|c|c|c|c|c|c|c|}
\hline \multirow[t]{2}{*}{ Risk factors } & \multicolumn{6}{|c|}{ Adjusted odds ratio for neonatal death in 3-7 days ( $95 \%$ confidence interval) } \\
\hline & Model $1^{*}$ & Model $2^{*}$ & Model $3^{*}$ & Model $4^{*}$ & Model $5^{*}$ & Model $6^{*}$ \\
\hline $\begin{array}{l}\text { Push/pull done during delivery by the } \\
\text { health provider }\end{array}$ & & & & & $2.55(1.33-4.86)$ & $1.81(0.93-3.51)$ \\
\hline \multicolumn{7}{|l|}{ Entangled cord around the baby's neck } \\
\hline No & & & & & 1.00 & \\
\hline Yes & & & & & $1.47(0.63-3.47)^{\ddagger}$ & \\
\hline Do not know & & & & & $0.95(0.43-2.09)^{\ddagger}$ & \\
\hline Breech presentation of the baby & & & & & $0.95(0.36-2.46)^{\ddagger}$ & \\
\hline \multicolumn{7}{|l|}{ Antiseptic cord care } \\
\hline Yes & & & & & 1.00 & \\
\hline No & & & & & $0.99(0.60-1.64)^{\ddagger}$ & \\
\hline Do not know & & & & & $1.20(0.62-2.31)^{\ddagger}$ & \\
\hline \multicolumn{7}{|l|}{ Baby put in the incubator } \\
\hline No & & & & & & 1.00 \\
\hline Yes & & & & & & $3.28(1.88-5.75)$ \\
\hline $\begin{array}{l}\text { Baby received delayed bathing, } \\
\text { skin-to-skin care, and immediate } \\
\text { breastfeeding }\end{array}$ & & & & & & $1.25(0.54-2.93)$ \\
\hline $\begin{array}{l}\text { Received postnatal care within } \\
1 \text { week of birth }\end{array}$ & & & & & & $1.48(0.91-2.39)$ \\
\hline \multicolumn{7}{|l|}{$\begin{array}{l}\text { Illness and treatment in the neonatal } \\
\text { period }\end{array}$} \\
\hline No illness & & & & & & 1.00 \\
\hline Untreated illness & & & & & & $15.71(9.10-27.13)$ \\
\hline III and out-patient treatment sought & & & & & & $3.82(1.84-7.92)$ \\
\hline Illness that required hospitalization & & & & & & $22.34(11.21-44.52)$ \\
\hline
\end{tabular}

*Model adjusted for sex of the baby and place of residence

${ }^{\ddagger} P \geq 0.2$ and hence excluded from the sequential model

compared with the private facility after birth. A significantly higher proportion of neonates who died at 3-7 days were discharged alive from the public (94.4\%) as compared with private facilities (63.6\%), with the mean days of stay at the facility before discharge lower in the former. A similar proportion of neonates who died at 827 days were discharged alive from the public (90.5\%) as compared with the private facility $(95.7 \%)$.

\section{Causes of death for neonatal mortality}

The distribution of causes of death varied for the three sub-categories of neonatal deaths (Fig. 2). Birth asphyxia (61.1\%) was the leading cause of death in $0-2$ days followed by preterm delivery (22.1\%); pneumonia (34.5\%), preterm delivery (33.7\%), and meningitis/sepsis (20.1\%) in 3-7 days; and meningitis/sepsis (30.6\%) and pneumonia (29.1\%) followed by preterm delivery (26.2\%) in 8-27 days.

Varying patterns for the cause of death were seen based on place of delivery in the age sub-groups (Additional file 4: Figure S2). The proportion of preterm delivery deaths was the least (16.6\%) and birth asphyxia was the most $(67.5 \%)$ for home deliveries as compared with the facility deliveries in $0-2$-day deaths $(24.5 \%$ and $58.4 \%$, respectively). In 3-7-day deaths, the proportion of meningitis/sepsis was higher in public sector (24\%) and home deliveries $(22.6 \%)$ as compared to the private sector deliveries $(7.9 \%)$ whereas the proportion of deaths due to congenital malformation (11.7\%) and birth asphyxia (11.1\%) was the highest in private sector deliveries. Preterm delivery accounted for $52.2 \%$ of the causes of death at home deliveries in 3-7-day deaths. Similar varying patterns for the causes of death were seen based on the place of delivery, particularly for preterm delivery and meningitis/sepsis, in 8-27-day deaths.

\section{Discussion}

The estimated NMR in Bihar was 24.7 deaths per 1000 live births in 2016, a significant reduction of $23 \%$ from 2011 , which was driven by the reduction in the $0-2$-day mortality with no significant change in 3-27 days mortality. The presentation of the risk factors and cause of death based on the age of neonate at the death and place of delivery and the place of death yield useful insights 
for programming to reduce neonatal mortality further in this population. Importantly, the splitting of the early neonatal age group of $0-7$ days into $0-2$ and 3-7 days highlights substantial differences not only in the mortality rate but also in the risk factors and causes of death between these sub-groups. These findings offer critical insights for better targeting of interventions in the early neonatal age groups and for monitoring and planning reduction in NMR. From the programme perspective, the fact that $0-2$-day mortality is reducing and is still more than half of NMR is an opportunity to enhance this reduction further. In addition, more effective focus on reducing 3-7- and 8-27-day mortality is also needed based on its major risk factors and causes.

The 0-2-day NMR was 2.3 times higher than the 3-7day NMR in 2016. Even with a decline of $35 \%$ between 2011 and 2016, 0-2 days mortality accounted for 53.4\% of the total neonatal mortality in 2016. Though this study was not designed to capture the possible reasons for 0-2-day NMR decline, the decrease corroborates with the increased coverage of facility deliveries, public sector in particular, in this population between 2011 and 2016 [7], and improvements in infection control and intrapartum practices in high delivery volume public sector facilities undertaken through the nurse mentoring in the BTSP in Bihar [19]. With regard to the risk factors, a gestation period of $\leq 8$ months was associated with neonatal deaths across the three age sub-groups; however, the highest risk was documented for 0-2-day deaths. It is estimated that $60 \%$ of all preterm births are in South Asia and sub-Saharan Africa, and these births account for $80 \%$ of neonatal deaths in these regions [2022]. A massive $82.8 \%$ of the neonatal deaths in India in 2017 could be attributed to low birth weight and short gestation [23], and its contribution to DALYs is higher in Bihar than the national average [4]. As the pregnancy length was captured in months in our study, it is difficult to comment on whether the premature babies were very or moderately preterm [24]. Preterm labour is considered to be a syndrome initiated by multiple mechanisms, and more understanding in the classification of preterm and of its risk factors is needed in this population, both for spontaneous and provider-initiated preterm births [25-27]. The obstetric complications including breech position presentation, pregnancy with multiple foetuses, cord around the baby's neck, and deliveries with "push and forceful pull" were associated with 0-2 days mortality, but only pregnancy with multiple foetuses was associated with 3-27 days mortality in this study. In addition to poor skills of staff providing emergency obstetric care in India [28-32], several other related health system barriers have been identified for emergency obstetric care, including the inadequacy of staff, equipment, and accountability [33]. The need for improving the emergency neonatal care is further highlighted by the causes of death in 0-2 days with birth asphyxia accounting for $61 \%$ and preterm births for $22 \%$ of these deaths. The proportion of deaths attributed to birth asphyxia decreased thereafter, and home births had a slightly higher proportion of these deaths in 0-2 days. Birth asphyxia and preterm births are known to account for the majority of deaths in the early neonatal period [22, 34]. Emergency neonatal care that includes management of asphyxia and extra care for low birth weight and preterm babies is one of the most cost-effective intervention packages to save newborns [35]. The shortage of appropriately trained human resources is recognized as a major bottleneck by INAP to improve quality of care for complicated deliveries [3, 36]. In addition, these data also point to equip human resources with the ability to manage birth asphyxia and preterm through prompt identification, stabilization, and appropriate referral [22], and to improve the understanding of neonatal mortality by gestation months to develop facility- and communitybased interventions to better manage the preterm newborns.

The absence of antiseptic cord care, delivering in the private sector and at home, being a male, and being the firstborn were associated with a higher risk of death in 0-2 days period but not in the 3-27 days period. Despite the dry cord care recommendation for all births by the Ministry of Health in India [37], antiseptic for cord care was reported in one quarter of the deliveries in this study which was associated with a lower 0-2-day mortality. We have previously reported similar results from this population highlighting that the application of readily available gentian violet on the cord after birth in less developed settings should be assessed further for its potential beneficial influence on neonatal mortality [38]. The 0-2-day mortality was higher both in the private facility and home births as compared with the public facility births. In the last 5 years, the proportion of home births has declined significantly by $20.5 \%$ but that of private facility births has remained unchanged in this population [7]. The home deliveries were predominately conducted by untrained birth attendants such as untrained Dai, family member, and friends rather than a skilled birth attendant in this population [8]. Ways to promote safe facility deliveries in women preferring home delivery by addressing relevant barriers for facility delivery and improving birth preparedness for those preferring home delivery are needed to address 0-2-day neonatal mortality [39-41]. Interpretation of a higher 02-day mortality in the private facilities should take into account the context of referred deliveries in this population and the finding of higher mortality in deliveries with obstetric complications and among the referred deliveries [8]. It is well known that the private sector provides 
Table 5 Results of sequential multiple logistic regression models for the association of neonatal deaths in 8-27 days after birth with select risk factors in the Indian state of Bihar

\begin{tabular}{|c|c|c|c|c|c|c|}
\hline \multirow[t]{2}{*}{ Risk factors } & \multicolumn{6}{|c|}{ Adjusted odds ratio for neonatal death in 8-27 days ( $95 \%$ confidence interval) } \\
\hline & Model $1^{*}$ & Model $2^{*}$ & Model $3^{*}$ & Model $4^{*}$ & Model $5^{*}$ & Model $6^{*}$ \\
\hline Rural place of residence & $1.64(0.59-4.56)$ & $1.64(0.59-4.56)$ & $1.64(0.57-4.71)$ & $1.74(0.59-5.17)$ & $1.62(0.57-4.62)$ & $1.33(0.47-3.81)$ \\
\hline Boy baby & $1.33(0.88-2.00)$ & $1.30(0.86-1.96)$ & $1.47(0.95-2.27)$ & $1.44(0.93-2.24)$ & $1.53(0.99-2.37)$ & $1.31(0.84-2.05)$ \\
\hline \multicolumn{7}{|l|}{ Wealth index quartile } \\
\hline । & & $2.49(1.26-4.92)$ & $2.89(1.38-6.05)$ & $3.47(1.63-7.36)$ & $4.08(1.88-8.87)$ & $3.77(1.73-8.23)$ \\
\hline$\|$ & & $1.92(0.94-3.88)$ & $2.47(1.17-5.22)$ & $2.89(1.34-6.20)$ & $3.31(1.51-7.23)$ & $2.88(1.32-6.29)$ \\
\hline III & & $2.00(1.00-4.03)$ & $2.48(1.20-5.13)$ & $2.47(1.15-5.31)$ & $2.63(1.22-5.67)$ & $2.93(1.37-6.26)$ \\
\hline IV & & 1.00 & 1.00 & 1.00 & 1.00 & 1.00 \\
\hline \multicolumn{7}{|l|}{ Maternal age } \\
\hline 15-19years & & 1.00 & & & & \\
\hline 20-24 years & & $1.13(0.39-3.24)^{\ddagger}$ & & & & \\
\hline $25-29$ years & & $0.92(0.30-2.82)^{\ddagger}$ & & & & \\
\hline$\geq 30$ years & & $1.39(0.43-4.47)^{\ddagger}$ & & & & \\
\hline Any tobacco use ever & & $0.69(0.17-2.81)^{\ddagger}$ & & & & \\
\hline Null parity & & $1.02(0.58-1.79)^{\ddagger}$ & & & & \\
\hline $\begin{array}{l}\text { Maternal history of high blood pressure } \\
\text { irrespective of pregnancy }\end{array}$ & & $0.64(0.09-4.62)^{\ddagger}$ & & & & \\
\hline $\begin{array}{l}\text { No maternal antenatal care visit during } \\
\text { pregnancy }\end{array}$ & & & $1.22(0.71-2.09)^{\ddagger}$ & & & \\
\hline $\begin{array}{l}\text { Mother did not receive } 2 \text { tetanus toxoid } \\
\text { injections during pregnancy }\end{array}$ & & & $1.29(0.78-2.15)^{\ddagger}$ & & & \\
\hline $\begin{array}{l}\text { Mother did not consume iron folic acid tablets } \\
\text { during pregnancy }\end{array}$ & & & $0.96(0.61-1.49)^{\ddagger}$ & & & \\
\hline Pregnancy with multiple foetuses & & & $9.88(5.41-18.03)$ & $11.89(6.63-21.34)$ & $10.57(5.86-19.07)$ & $11.77(6.43-21.53)$ \\
\hline $\begin{array}{l}\text { Maternal hypertension in the last trimester } \\
\text { of pregnancy }\end{array}$ & & & $1.43(0.42-4.93)^{\ddagger}$ & & & \\
\hline $\begin{array}{l}\text { Mother had malaria in the last trimester } \\
\text { of pregnancy }\end{array}$ & & & $0.35(0.05-2.70)^{\ddagger}$ & & & \\
\hline \multicolumn{7}{|l|}{ Diagnosed with syphilis during pregnancy } \\
\hline No & & & 1.00 & & & \\
\hline Yes & & & NA & & & \\
\hline Do not know & & & $1.07(0.45-2.52)^{\ddagger}$ & & & \\
\hline $\begin{array}{l}\text { Mother had a fever in the last } 3 \text { months } \\
\text { of pregnancy }\end{array}$ & & & $0.88(0.50-1.57)^{\ddagger}$ & & & \\
\hline $\begin{array}{l}\text { Mother had convulsions in the last } 3 \text { months } \\
\text { of pregnancy }\end{array}$ & & & $0.61(0.27-1.37)^{\ddagger}$ & & & \\
\hline $\begin{array}{l}\text { Mother is informed the baby was not growing } \\
\text { adequately inside the womb }\end{array}$ & & & $2.68(1.22-5.89)$ & $2.00(0.89-4.48)$ & $2.06(0.92-4.58)$ & $1.52(0.68-3.39)$ \\
\hline \multicolumn{7}{|l|}{ Gestation period } \\
\hline 8 months or less & & & $10.76(5.86-19.78)$ & $11.80(6.45-21.60)$ & $10.68(5.81-19.63)$ & $6.15(3.18-11.87)$ \\
\hline$>8$ months & & & 1.00 & 1.00 & 1.00 & 1.00 \\
\hline Deferred delivery & & & & $2.20(0.58-8.31)^{\ddagger}$ & & \\
\hline Spontaneous labour & & & & $1.24(0.77-2.01)^{\ddagger}$ & & \\
\hline Foul-smelling liquor & & & & $1.50(0.66-3.39)^{\ddagger}$ & & \\
\hline Labour for more than 12 hours & & & & $0.97(0.53-1.77)^{\ddagger}$ & & \\
\hline \multicolumn{7}{|l|}{ Place of delivery } \\
\hline Public facility & & & & & 1.00 & 1.00 \\
\hline Private facility & & & & & $1.86(1.01-3.44)$ & $1.38(0.76-2.52)$ \\
\hline Home & & & & & $1.14(0.69-1.87)$ & $1.35(0.79-2.33)$ \\
\hline Vaginal delivery & & & & & $1.08(0.48-2.42)^{\ddagger}$ & \\
\hline
\end{tabular}


Table 5 Results of sequential multiple logistic regression models for the association of neonatal deaths in 8-27 days after birth with select risk factors in the Indian state of Bihar (Continued)

\begin{tabular}{|c|c|c|c|c|c|c|}
\hline \multirow[t]{2}{*}{ Risk factors } & \multicolumn{6}{|c|}{ Adjusted odds ratio for neonatal death in $8-27$ days ( $95 \%$ confidence interval) } \\
\hline & Model $1^{*}$ & Model $2^{*}$ & Model $3^{*}$ & Model $4^{*}$ & Model $5^{*}$ & Model $6^{*}$ \\
\hline $\begin{array}{l}\text { Push/pull done during delivery } \\
\text { by the health provider }\end{array}$ & & & & & $0.55(0.17-1.81)^{\ddagger}$ & \\
\hline \multicolumn{7}{|l|}{$\begin{array}{l}\text { Entangled cord around the } \\
\text { baby's neck }\end{array}$} \\
\hline No & & & & & 1.00 & \\
\hline Yes & & & & & $1.06(0.38-2.98)^{\ddagger}$ & \\
\hline Do not know & & & & & $1.23(0.58-2.61)^{\ddagger}$ & \\
\hline Breech presentation of the baby & & & & & $1.58(0.68-3.69)^{\ddagger}$ & \\
\hline \multicolumn{7}{|l|}{ Antiseptic cord care } \\
\hline Yes & & & & & 1.00 & \\
\hline No & & & & & $1.31(0.78-2.21)^{\ddagger}$ & \\
\hline Do not know & & & & & $1.06(0.50-2.26)^{\ddagger}$ & \\
\hline \multicolumn{7}{|l|}{ Baby put in the incubator } \\
\hline No & & & & & & 1.00 \\
\hline Yes & & & & & & $2.72(1.49-4.96)$ \\
\hline $\begin{array}{l}\text { Baby received delayed bathing, skin-to-skin } \\
\text { care, and immediate breastfeeding }\end{array}$ & & & & & & $1.02(0.46-2.27)$ \\
\hline Received postnatal care within 1 week of birth & & & & & & $1.43(0.85-2.42)$ \\
\hline \multicolumn{7}{|l|}{ Illness and treatment in the neonatal period } \\
\hline No illness & & & & & & 1.00 \\
\hline Untreated illness & & & & & & $5.50(3.11-9.74)$ \\
\hline III and out-patient treatment sought & & & & & & $2.83(1.49-5.37)$ \\
\hline Illness that required hospitalization & & & & & & $12.16(6.21-23.79)$ \\
\hline
\end{tabular}

most of the emergency obstetric care in India and also serves as a referral facility for the public sector for complicated deliveries $[42,43]$. To address the neonatal mortality in such deliveries, BTSP is exploring a partnership with the private sector for improved quality of care, which can be considered under the INAP as well $[3,44]$. Ensuring quality of care in a private sector is important with the increasing involvement of the private sector in the universal health coverage agenda of the Government of India [45].

A $20.1 \%$ decline of borderline statistical significance in overall NMR was seen in boys between 2011 and 2016. Boys accounted for $55.6 \%$ of all neonatal deaths in 2016, and the NMR was similar for both sexes in 2016. A higher risk of neonatal mortality in boys accounted for by biological differences between boys and girls that favour girl survival during the neonatal period is known [46] and is seen in 0-2-day mortality in this population. As this study was not designed to capture the reasons for NMR decline by sex, this finding needs to be looked into further given India's obsession with boy child to explore if access to better services or treatment factors accounts for this differential decline by sex in this population [47].
The 3-27 days mortality accounted for $47 \%$ of all neonatal mortality in 2016 in this population with illness during the neonatal period being its most significant predictor. This is also reflected in the cause of death distribution with pneumonia and meningitis/sepsis accounting for a major proportion of these deaths in addition to preterm births. Though home visitation during the neonatal period by a health worker to check on the baby for early identification of danger signs and prompt treatment and referral is meant to be part of the routine health system [48], its coverage is quite poor [49, 50]. In this population, only one third of the neonates who survived $>2$ days received a postnatal care visit in the first week of birth. The latest DHS survey 20152016 reported coverage of postnatal care visit in $24 \mathrm{~h}$ after birth at $11.2 \%$ for Bihar [16]. Babies who were sick and not treated and those who needed hospitalization suggesting increased severity of illness were significantly more likely to die during this period. The preterm deaths continued to account for $26-33 \%$ of deaths in $3-$ 27 days, thereby highlighting the need for effective postnatal care in these babies. In addition, the illness- and treatment-seeking patterns presented for various illness symptoms in the community offer insight into the 


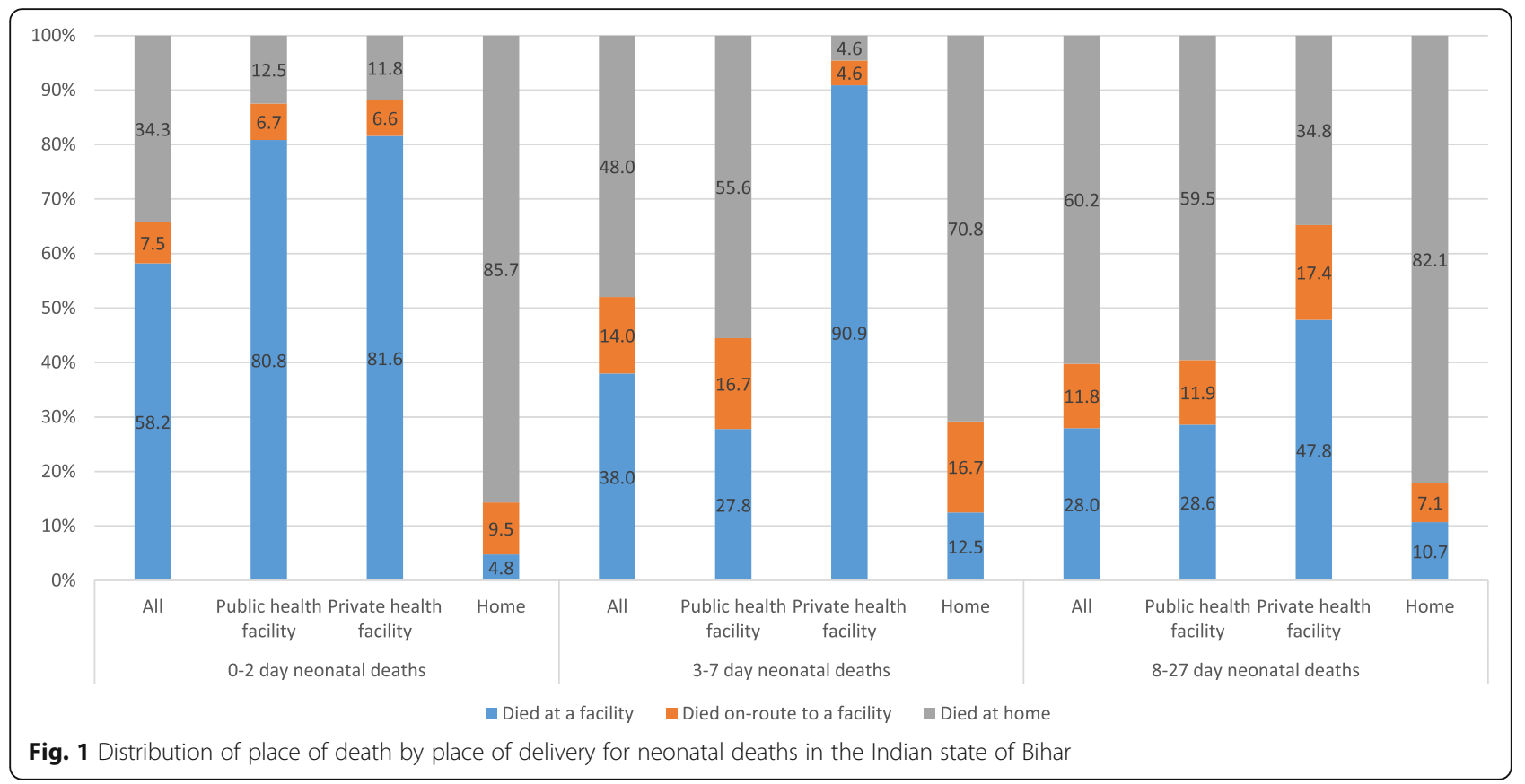

challenges at the community level for early identification and treatment of sick babies. In addition to targeting the families of low birth weight and premature babies for extra care, the INAP could also include babies who are put in the incubator post-delivery for extra postnatal care attention and consider intervening at the community level to improve early identification of danger signs and prompt treatment and referral $[3,49]$.

Two doses of TT immunization are among the established and cost-effective interventions to save newborn babies [35]. Pregnancies without the TT doses were significantly more likely to result in $0-2$ and 3-7-day mortality in this study. Over the last 5 years, a significant decline of $12.1 \%$ in TT immunization coverage during pregnancy was seen in this population [7]. This drop in coverage reflects poor quality of ANC services as TT doses are administered under the ANC interventions. Furthermore, pregnancies with no ANC were associated with a higher risk of 3-7-day mortality in this study. Improving ANC services is imperative to reduce adverse pregnancy outcomes as the specific interventions delivered in this period are meant to prevent or identify and treat infections, pregnancy-induced conditions, and undernutrition $[36,51,52]$. The possible reasons for the inadequacy of assessment or knowledge of the risk factors such as syphilis, diabetes, and hypertension in pregnant women have been previously reported by us from this population [8], highlighting that neonatal mortality cannot be addressed fully unless the quality of ANC services improves to deliver maternal interventions. In this direction, the
Government of India has recently taken steps to address the coverage and quality of ANC services to pregnant women through a specific programme [53].

In order to address neonatal mortality comprehensively, it is important to understand where the babies die in addition to the cause of death and risk factors for neonatal mortality. Overall, $42 \%$ of the neonates died at home, and babies who were born at home were also most likely to die at home irrespective of the age at death. This finding is of concern as it highlights not only the limited access to emergency obstetric care but also the limited access to illness treatment during the neonatal period for this sub-group of babies. Targeting the barriers to uptake of institutional delivery and understanding health-seeking behaviour practices in this group would be important to reduce neonatal mortality in home deliveries [54-58]. A significantly different pattern was seen for facility births by age sub-groups. Though the majority of 0-2-day deaths occurred at the facility irrespective of the type of health facility, the proportion of public sector births dying at the facility was significantly lower than the private sector births for 3-27-day deaths. Also, as the mean days of stay were significantly lower in the former than the latter, further in-depth exploration would be useful to understand the context of duration of facility stay in relation to the delivery complications or other barriers such as costs and quality of care in addition to the treatment-seeking behaviour to develop strategies to reduce neonatal mortality [59].

There are some limitations to the study findings. As is the case with surveys, the findings should be interpreted within the context of recall bias of the respondent. The 

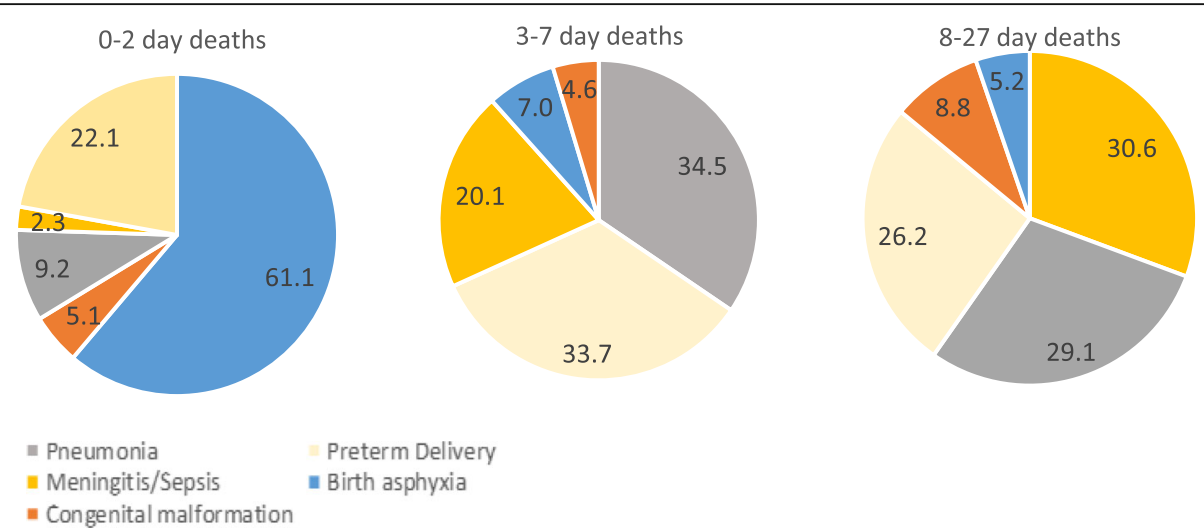

- Birth asphyxia

- Congenital malformation

Fig. 2 Distribution of causes of death using verbal autopsy interviews by the three age sub-groups in the Indian state of Bihar

gestational age was captured in months instead of weeks as the pregnancy length in India is reported in months. The last menstrual period forms the basis for most and is considered a reliable estimate for measuring gestational age in both developing and developed country settings $[60,61]$. Strengthening of the numerator and denominator for neonatal mortality estimation by documenting all in/out-migration among the reproductive age women with pregnancy outcome in the period of interest and differentiation of stillbirth from immediate neonatal death from enumeration through the analysis is a major strength. Presenting the findings by the three age sub-groups supports the need for a continuum of care as the core principle to address the further decline in neonatal mortality [62]. We used a hierarchical approach to the risk factor analysis that gave importance to distal determinants of neonatal mortality and have presented results in a manner that allows for better understanding of the association of various risk factors of interest [13].

With the variations highlighted in the decline in NMR, and in drivers and causes of death of neonatal mortality by the age sub-groups, we strongly recommend that the INAP monitor neonatal mortality in these age sub-groups by splitting the early neonatal period into 0-2 and 3-7 days. Such monitoring will also ensure that every newborn is taken into account through a framework of integrated packages of service delivery for the health of mothers and newborn babies along the continuum of care $[1,62]$. Our data on neonatal mortality epidemiology by the age subgroups can be used to specifically adapt the evidencebased intervention framework to deliver across the continuum of care from pregnancy to the neonatal period [62]. Furthermore, as the neonates belonging to wealth index strata other than the highest were more likely to die in this population, it is imperative to address inequity across the continuum of care by reaching every newborn to further reduce neonatal mortality [63].

\section{Conclusions}

Given the variations in the risk factors and causes of death in the three age sub-groups as shown in this study, it would be useful to rethink the current categorization of neonatal age groups and split the early neonatal group of 0-7 days into 0-2 days and 3-7 days groups to plan interventions and monitor mortality changes more specifically in these two periods.

\section{Additional files}

Additional file 1: Table S1. Basic descriptive during labour and delivery for all live births between January and December 2016 and for neonatal deaths in $0-2,3-7$, and $8-27$ days by the place of delivery for those who participated in the detailed interview. (DOCX $37 \mathrm{~kb}$ )

Additional file 2: Table S2. Survival status at discharge post-birth and mean days of facility stay for neonates born at a facility in the Indian state of Bihar. (DOCX $22 \mathrm{~kb}$ )

Additional file 3: Figure S1. Distribution of illness symptoms (not mutually exclusive) and treatment sought for that symptom among newborns who survived 3 days or more in the Indian state of Bihar. (DOCX 23 kb)

Additional file 4: Figure S2. Distribution of causes of death using verbal autopsy interviews by place of delivery for the three age sub-groups in the Indian state of Bihar. (DOCX $66 \mathrm{~kb}$ )

\section{Abbreviations}

ANC: Antenatal care; BTSP: Bihar Technical Support Programme;

Cl: Confidence interval; INAP: Indian Newborn Action Plan; NMR: Neonatal mortality rate; $\pi$ : Tetanus toxoid

\section{Acknowledgements}

We thank the study participants for providing the interviews. We acknowledge the contributions of Nayan Kumar, Navin Kumar, Dilip Parida, Vipul Singhal, Mritunjay Kumar, and Vivek Kumar, and the entire field team in the data collection. We thank Amit Kumar for the data management.

\section{Authors' contributions}

RD and GAK had full access to the data in the study and take full responsibility for the integrity of the data and accuracy of the data analysis. RD, GAK, and LD conceptualized the study. RD guided the data analysis and drafted the manuscript. GAK performed the data analysis. MA guided the 
data collection. MA, DB, YA, and PN contributed to the data analysis and interpretation. LD contributed to the drafting of the manuscript and interpretation. All authors approved the final manuscript.

\section{Funding}

This survey was carried out under a grant by the Bill \& Melinda Gates Foundation (OPP1142884).

\section{Availability of data and materials}

All data generated or analysed during this study are included in this published article and its additional information files.

\section{Ethics approval and consent to participate}

This study was approved by the Institutional Ethics Committee of the Public Health Foundation of India. All participants provided written informed consent, and for those who could not read or write, the participant information sheet and consent form were explained by the trained interviewer and a thumb impression is obtained.

\section{Consent for publication}

Not applicable.

\section{Competing interests}

$\mathrm{DB}, \mathrm{YA}$, and PN are employees of the Bill \& Melinda Gates Foundation, India Country Office, New Delhi. The other authors declare that they have no competing interests.

\section{Author details}

'Public Health Foundation of India, Sector 44, Institutional Area, Gurugram, National Capital Region, India. ${ }^{2}$ Institute for Health Metrics and Evaluation, University of Washington, Seattle, USA. ${ }^{3}$ Bill \& Melinda Gates Foundation, India Country Office, New Delhi, India.

Received: 5 March 2019 Accepted: 18 June 2019

\section{Published online: 19 July 2019}

\section{References}

1. World Health Organization and UNICEF. Every Newborn: an action plan to end preventable deaths. South Africa: WHO and UNICEF; 2014.

2. GBD 2016 Mortality Collaborators. Global, regional, and national under-5 mortality, adult mortality, age-specific mortality, and life expectancy, 19702016: a systematic analysis for the Global Burden of Disease Study 2016. Lancet. 2017:390(10100):1084-150.

3. Ministry of Health and Family Welfare, Government of India. INAP: India Newborn Action Plan. New Delhi: Government of India; 2014

4. India State-level Disease Burden Initiative Collaborators. Nations within a nation: variations in epidemiological transition across the states of India, 1990-2016 in the Global Burden of Disease Study. Lancet. 2017;390(10111): $2437-60$.

5. Indian Council of Medical Research, Public Health Foundation of India, Institute for Health Metrics and Evaluation. India: Health of The Nation's States - the India state level disease burden initiative. New Delhi: ICMR, PHFI, IHME; 2017.

6. Bihar Technical Support Programme [https://www.careindia.org/project/ technical-assistance-to-the-government-of-bihar-improving-health-nutritioncoverage-and-outcomes/]. Accessed 25 June 2019.

7. Kumar GA, Dandona R, Chaman P, Singh P, Dandona L. A population-based study of neonatal mortality and maternal care utilization in the Indian state of Bihar. BMC Pregnancy Childbirth. 2014;14:357.

8. Dandona R, Kumar GA, Akbar M, Bhattacharya D, Nanda P, Dandona L. Deferred and referred deliveries contribute to stillbirths in the Indian state of Bihar: results from a population-based survey of all births. BMC Med. 2019;17:28.

9. C.D. Blockwise Primary Census Abstract Data (PCA) - Bihar [http:// censusindia.gov.in/pca/cdb_pca_census/Houselisting-housing-BR.html]. Accessed 19 Jan 2019.

10. Flaxman AD, Vahdatpour A, James SL, Birnbaum JK, Murray CJ. Direct estimation of cause-specific mortality fractions from verbal autopsies: multisite validation study using clinical diagnostic gold standards. Popul Health Metrics. 2011;9:35.
11. Serina P, Riley I, Stewart A, Flaxman AD, Lozano R, Mooney MD, Luning R, Hernandez B, Black R, Ahuja R, et al. A shortened verbal autopsy instrument for use in routine mortality surveillance systems. BMC Med. 2015;13:302.

12. Neonatal mortality rate (NMR) [https://www.measureevaluation.org/prh/rh indicators/womens-health/nb/neonatal-mortality-rate-nmr]. Accessed 14 Dec 2018.

13. Victora CG, Huttly SR, Fuchs SC, Olinto MT. The role of conceptual frameworks in epidemiological analysis: a hierarchical approach. Int J Epidemiol. 1997;26(1):224-7.

14. Hirst JE, Villar J, Victora CG, Papageorghiou AT, Finkton D, Barros FC, Gravett MG, Giuliani F, Purwar M, Frederick IO, et al. The antepartum stillbirth syndrome: risk factors and pregnancy conditions identified from the INTERGROWTH-21(st) Project. BJOG. 2018;125(9):1145-53.

15. Vittinghoff $E, M c C u l l o c h ~ C E$. Relaxing the rule of ten events per variable in logistic and Cox regression. Am J Epidemiol. 2007;165(6):710-8.

16. International Institute for Population Sciences (IIPS). National Family Health Survey (NFHS-4), India, 2015-16: Bihar. Mumbai: IIPS; 2017

17. Flaxman AD, Vahdatpour A, Green S, James SL, Murray CJ. Random forests for verbal autopsy analysis: multisite validation study using clinical diagnostic gold standards. Popul Health Metrics. 2011;9:29.

18. Serina P, Riley I, Stewart A, James SL, Flaxman AD, Lozano R, Hernandez B, Mooney MD, Luning R, Black $R$, et al. Improving performance of the Tariff Method for assigning causes of death to verbal autopsies. BMC Med. 2015; 13:291.

19. Das A, Nawal D, Singh MK, Karthick M, Pahwa P, Shah MB, Mahapatra T, Ranjan K, Chaudhuri I. Evaluation of the mobile nurse training (MNT) intervention - a step towards improvement in intrapartum practices in Bihar, India. BMC Pregnancy Childbirth. 2017;17(1):266.

20. Blencowe $H$, Cousens $S$, Oestergaard MZ, Chou D, Moller AB, Narwal R, Adler A, Vera Garcia C, Rohde S, Say L, et al. National, regional, and worldwide estimates of preterm birth rates in the year 2010 with time trends since 1990 for selected countries: a systematic analysis and implications. Lancet. 2012;379(9832):2162-72.

21. Lawn JE, Blencowe H, Oza S, You D, Lee AC, Waiswa P, Lalli M, Bhutta Z, Barros AJ, Christian P, et al. Every Newborn: progress, priorities, and potential beyond survival. Lancet. 2014:384(9938):189-205.

22. Oza S, Lawn JE, Hogan DR, Mathers C, Cousens SN. Neonatal cause-of-death estimates for the early and late neonatal periods for 194 countries: 20002013. Bull World Health Organ. 2015;93(1):19-28.

23. GBD Compare 2017. [https://vizhub.healthdata.org/gbd-compare/]. Accessed 4 Feb 2019.

24. Lawn JE, Gravett MG, Nunes TM, Rubens CE, Stanton C. Global report on preterm birth and stillbirth (1 of 7): definitions, description of the burden and opportunities to improve data. BMC Pregnancy Childbirth. 2010; 10(Suppl 1):S1.

25. Goldenberg RL, Culhane JF, lams JD, Romero R. Epidemiology and causes of preterm birth. Lancet. 2008;371(9606):75-84

26. Lackritz EM, Wilson CB, Guttmacher AE, Howse JL, Engmann CM, Rubens $C E$, Mason EM, Muglia L, Gravett MG, Goldenberg RL, et al. A solution pathway for preterm birth: accelerating a priority research agenda. Lancet Glob Health. 2013;1(6):e328-30.

27. Kramer MS, Papageorghiou A, Culhane J, Bhutta Z, Goldenberg RL, Gravett M, lams JD, Conde-Agudelo A, Waller S, Barros F, et al. Challenges in defining and classifying the preterm birth syndrome. Am J Obstet Gynecol. 2012;206(2):108-12.

28. Chaturvedi S, Randive B, Diwan V, De Costa A. Quality of obstetric referral services in India's JSY cash transfer programme for institutional births: a study from Madhya Pradesh province. PLoS One. 2014;9(5):e96773.

29. Chaturvedi S, Upadhyay S, De Costa A. Competence of birth attendants at providing emergency obstetric care under India's JSY conditional cash transfer program for institutional delivery: an assessment using case vignettes in Madhya Pradesh province. BMC Pregnancy Childbirth. 2014;14:174.

30. Singh S, Doyle P, Campbell OM, Mathew M, Murthy GV. Referrals between public sector health institutions for women with obstetric high risk, complications, or emergencies in India - a systematic review. PLoS One. 2016;11(8):e0159793.

31. Ameh C, Msuya S, Hofman J, Raven J, Mathai M, van den Broek N. Status of emergency obstetric care in six developing countries five years before the MDG targets for maternal and newborn health. PLoS One. 2012;7(12): e49938. 
32. Patel AB, Prakash AA, Raynes-Greenow C, Pusdekar YV, Hibberd PL. Description of inter-institutional referrals after admission for labor and delivery: a prospective population based cohort study in rural Maharashtra India. BMC Health Serv Res. 2017;17(1):360.

33. Dickson KE, Simen-Kapeu A, Kinney MV, Huicho L, Vesel L, Lackritz E, de Graft JJ, von Xylander S, Rafique N, Sylla M, et al. Every Newborn: healthsystems bottlenecks and strategies to accelerate scale-up in countries. Lancet. 2014;384(9941):438-54.

34. Million Death Study Collaborators. Changes in cause-specific neonatal and 1-59-month child mortality in India from 2000 to 2015: a nationally representative survey. Lancet. 2017;390(10106):1972-80.

35. Darmstadt GL, Bhutta ZA, Cousens S, Adam T, Walker N, de Bernis L. Evidence-based, cost-effective interventions: how many newborn babies can we save? Lancet. 2005;365(9463):977-88.

36. Das JK, Rizvi A, Bhatti Z, Paul V, Bahl R, Shahidullah M, Manandhar D, Stanekzai H, Amarasena S, Bhutta ZA. State of neonatal health care in eight countries of the SAARC region, South Asia: how can we make a difference? Paediatr Int Child Health. 2015;35(3):174-86.

37. Guidelines for Antenatal Care and Skilled Attendance at Birth by ANMs/ LHVs/SNs [http://www.nhp.gov.in/sites/default/files/anm_guidelines.pdf]. Accessed 14 Sept 2018.

38. Dandona R, Kochar PS, Kumar GA, Dandona L. Use of antiseptic for cord care and its association with neonatal mortality in a population-based assessment in Bihar state, India. BMJ Open. 2017;7(1):e012436.

39. Akshaya KM, Shivalli S. Birth preparedness and complication readiness among the women beneficiaries of selected rural primary health centers of Dakshina Kannada district, Karnataka, India. PloS One. 2017; 12(8):e0183739.

40. Solnes Miltenburg A, Roggeveen $Y$, Shields L, van Elteren M, van Roosmalen J, Stekelenburg J, Portela A. Impact of birth preparedness and complication readiness interventions on birth with a skilled attendant: a systematic review. PLoS One. 2015;10(11):e0143382.

41. Wilcox ML, Krupp K, Niranjankumar B, Srinivas V, Jaykrishna P, Arun A, Madhivanan P. Birth preparedness and place of birth in rural Mysore, India: a prospective cohort study. Midwifery. 2016;34:245-52.

42. Salazar M, Vora K, De Costa A. The dominance of the private sector in the provision of emergency obstetric care: studies from Gujarat, India. BMC Health Serv Res. 2016;16:225.

43. Mony PK, Krishnamurthy J, Thomas A, Sankar K, Ramesh BM, Moses S, Blanchard J, Avery L. Availability and distribution of emergency obstetric care services in Karnataka state, South India: access and equity considerations. PLoS One. 2013:8(5):e64126.

44. De Costa A, Vora KS, Ryan K, Sankara Raman P, Santacatterina M, Mavalankar D. The state-led large scale public private partnership 'Chiranjeevi Program' to increase access to institutional delivery among poor women in Gujarat, India: how has it done? What can we learn? PLoS One. 2014;9(5):e95704

45. About Pradhan Mantri Jan Arogya Yojana (PM-JAY) [https://www.pmjay.gov. in/about-pmjay]. Accessed 15 Feb 2019.

46. Alkema L, Chao F, You D, Pedersen J, Sawyer CC. National, regional, and global sex ratios of infant, child, and under-5 mortality and identification of countries with outlying ratios: a systematic assessment. Lancet Glob Health. 2014;2(9):e521-30.

47. Office of Registrar General of India. Vital statistics of India based on the Civil Registration System. New Delhi: Government of India; 2016.

48. Ministry of Health and Family Welfare, Government of India: Operational guidelines on maternal and newborn health. Edited by Ministry of Health and Family Welfare. New Delhi; 2010.

49. Gogia S, Sachdev HS. Home visits by community health workers to prevent neonatal deaths in developing countries: a systematic review. Bull World Health Organ. 2010;88(9):658-666B.

50. Neogi SB, Sharma J, Chauhan M, Khanna R, Chokshi M, Srivastava R, Prabhakar PK, Khera A, Kumar R, Zodpey S, et al. Care of newborn in the community and at home. J Perinatol: official journal of the California Perinatal Association. 2016;36(s3):S13-7.

51. Yakoob MY, Lawn JE, Darmstadt GL, Bhutta ZA. Stillbirths: epidemiology, evidence, and priorities for action. Semin Perinatol. 2010;34(6):387-94.

52. Bhutta ZA, Yakoob MY, Lawn JE, Rizvi A, Friberg IK, Weissman E, Buchmann E, Goldenberg RL. Stillbirths: what difference can we make and at what cost? Lancet. 2011;377(9776):1523-38.

53. About Pradhan Mantri Surakshit Matritva Abhiyan [https://pmsma.nhp.gov. in/about-scheme/]. Accessed 15 Feb 2019.
54. Adamson PC, Krupp K, Niranjankumar B, Freeman AH, Khan M, Madhivanan $P$. Are marginalized women being left behind? A population-based study of institutional deliveries in Karnataka, India. BMC Public Health. 2012;12:30.

55. Bruce SG, Blanchard AK, Gurav K, Roy A, Jayanna K, Mohan HL, Ramesh BM, Blanchard JF, Moses S, Avery L. Preferences for infant delivery site among pregnant women and new mothers in Northern Karnataka, India. BMC Pregnancy Childbirth. 2015;15:49.

56. Gupta A, Fledderjohann J, Reddy H, Raman VR, Stuckler D, Vellakkal S. Barriers and prospects of India's conditional cash transfer program to promote institutional delivery care: a qualitative analysis of the supply-side perspectives. BMC Health Serv Res. 2018;18(1):40.

57. Thongkong N, van de Poel E, Roy SS, Rath S, Houweling TA. How equitable is the uptake of conditional cash transfers for maternity care in India? Evidence from the Janani Suraksha Yojana scheme in Odisha and Jharkhand. Int J Equity Health. 2017;16(1):48.

58. Kaushal M, Aggarwal R, Singal A, Shukla H, Kapoor SK, Paul VK. Breastfeeding practices and health-seeking behavior for neonatal sickness in a rural community. J Trop Pediatr. 2005;51(6):366-76

59. Saunik SJC, Nair R, Radkar A, Patil A, Irani S, Phadke M. Analysis of neonatal deaths in Maharashtra: policy implications. Int J Community Med Public Health. 2017:4(12):4513-9.

60. Lynch CD, Zhang J. The research implications of the selection of a gestational age estimation method. Paediatr Perinat Epidemiol. 2007; 21(Suppl 2):86-96.

61. Rosenberg RE, Ahmed AS, Ahmed S, Saha SK, Chowdhury MA, Black RE, Santosham M, Darmstadt GL. Determining gestational age in a low-resource setting: validity of last menstrual period. J Health Popul Nutr. 2009;27(3): 332-8.

62. Kerber KJ, de Graft-Johnson JE, Bhutta ZA, Okong P, Starrs A, Lawn JE. Continuum of care for maternal, newborn, and child health: from slogan to service delivery. Lancet. 2007;370(9595):1358-69.

63. What is Every Woman Every Child? [http://www.everywomaneverychild.org/ about/]. Accessed 15 Feb 2019.

\section{Publisher's Note}

Springer Nature remains neutral with regard to jurisdictional claims in published maps and institutional affiliations.

Ready to submit your research? Choose BMC and benefit from:

- fast, convenient online submission

- thorough peer review by experienced researchers in your field

- rapid publication on acceptance

- support for research data, including large and complex data types

- gold Open Access which fosters wider collaboration and increased citations

- maximum visibility for your research: over $100 \mathrm{M}$ website views per year

At $\mathrm{BMC}$, research is always in progress.

Learn more biomedcentral.com/submissions 